Portland State University

PDXScholar

\title{
Adolescent Executive Dysfunction and Distant Parental Relationships: Influences on Tobacco Use in Youth Under the Age of 18
}

Aaron M. Eisen

Portland State University

Follow this and additional works at: https://pdxscholar.library.pdx.edu/honorstheses

Let us know how access to this document benefits you.

\section{Recommended Citation}

Eisen, Aaron M., "Adolescent Executive Dysfunction and Distant Parental Relationships: Influences on Tobacco Use in Youth Under the Age of 18" (2019). University Honors Theses. Paper 694.

https://doi.org/10.15760/honors.711

This Thesis is brought to you for free and open access. It has been accepted for inclusion in University Honors Theses by an authorized administrator of PDXScholar. Please contact us if we can make this document more accessible: pdxscholar@pdx.edu. 
EXECUTIVE FUNCTIONS, RELATIONSHIPS, AND CIGARETTES

Adolescent Executive Dysfunction and Distant Parental Relationships:

Influences on Tobacco Use in Youth Under the Age of 18

Aaron M. Eisen

Honors Thesis 
EXECUTIVE FUNCTIONS, RELATIONSHIPS, AND CIGARETTES

\begin{abstract}
Substance use such as tobacco is common during the adolescent stage of development. Nicotine, the primary psychoactive compound in tobacco, is considered to be one of the most addictive drugs. Cigarette use has been associated with a wide range of health complications and is listed as one of the most preventable causes of disease in the United States with 480,000 smoking-related deaths per year. Those who use substances during adolescence are more likely to develop tobacco and other substance use disorders later in life. Further research on the underlying factors that predict cigarette use could support the development of new evidence-based preventative treatment interventions.
\end{abstract}

The goal of this study was to investigate the relationship between executive dysfunction measured by the Behavioral Rating Inventory of Executive Functions (BRIEF-2), distant parental relationships including parental support, monitoring, decision influence, and communication; and cigarette use two years later. The subjects $(n=503$; ages 12 through 18$)$ were all participants in the National Consortium on Alcohol and Neurodevelopment in Adolescents (NCANDA) study.

To explore these interactions, specific paths were tested in a multivariate longitudinal mediation analysis to measure both latent (executive functions and parental support) and observed (cigarette use in the past 365 days) variables. A confirmatory factor analysis was used to construct the latent variables and bivariate and multivariate models were used to assess these interactions further.

The results indicated that distant parental relationships and executive dysfunction predicted cigarette use in adolescent populations two years later. Distant parental relationships were also found to predict executive dysfunction and as expected both parental relationships and executive dysfunction acted as partial mediators. Although, the modest reduction in the relationship between parental relationships, executive functions, and cigarette use suggests the mediation hypotheses may not be 
EXECUTIVE FUNCTIONS, RELATIONSHIPS, AND CIGARETTES

truly be supported. Age and sex were found to be even greater predictors of cigarette use. Furthermore, significant sex differences were reported; the average female in the model had a (4.9\%) probability of being a cigarette smoker, while an average male had a (9.7\%) probability, future studies should explore these interactions further.

Preventative treatment interventions should aim to close the distance in a child-parental relationship by improving levels of parental support, actual monitoring, decision influence, and communication, which is also effective at reducing internalizing and externalizing behaviors associated with executive dysfunction and substance use. However, past research has shown social economic status may influence both executive functions and parental relationships. Adolescents who express characteristics of executive dysfunction, especially those who are closer to 18 years old and have distant parental relationships, should be a targeted population in these preventative interventions.

\section{Introduction}

Substance use such as tobacco is common during the adolescent stage of development. During this period, structural and functional changes within the prefrontal cortex (PFC) negatively impact selfregulation (Steinberg, 2008). Developmental changes in the PFC are likely what make adolescents more susceptible to risk-taking behaviors. Risk-taking declines during adulthood as changes in the PFC (during the adolescent stage of development) improve self-regulation (during adulthood). Regardless of this improvement in self-regulation during adulthood, an earlier onset of tobacco use is associated with an increased likelihood of remaining a tobacco user (Bonnie et al., 2015). The Center for Disease Control claims nearly nine out of ten cigarette smokers have tried their first cigarette by age 18 . Therefore, further research focused on the underlying factors that predict cigarette use in adolescents could support the development of preventative interventions. 
EXECUTIVE FUNCTIONS, RELATIONSHIPS, AND CIGARETTES

Nicotine, the primary psychoactive compound in tobacco, is considered to be one of the most addictive drugs, with only (3\%) of users able to successfully achieve cessation (Gamberino \& Gold, 1999). In the United States, of the 20 million people who quit using for at least one day, only about (10\%) remain abstinent one year later (Gamberino \& Gold, 1999). Cigarette use has been listed as one of the most preventable causes of diseases and death in the United States with 480,000 (approximately 280,000 men and 200,000 women) smoking-related deaths per year (Warren, Alberg, Kraft, \& Cummings, 2014). On average, smokers die 10-years earlier than non-smokers (Jha et al., 2013). Approximately 41,000 deaths per year are attributed to second-hand tobacco smoke alone (Warren et al., 2014). Past research has also found the duration of tobacco abstinence to be associated with fewer relapses in stimulant and opioid addicted rats (Gamberino \& Gold, 1999).

Age has been shown to be a predictive factor for many different types of substance use. Age of first use is generally younger for tobacco than drugs such as cocaine and heroin (Bracken, Rodolico, \& Hill, 2013). Levels of substance use tend to increase throughout adolescence and decrease during adulthood (Chen \& Jacobson, 2012). Considering gender, adolescent males exhibit higher levels of substance use with a greater degree of variation over time (Chen \& Jacobson, 2012). Past studies with various methodologies have provided mixed results about the interaction between race/ethnicity and substance use in adolescent populations (Chen \& Jacobson, 2012; Flannery, Vazsonyi, Torquati, \& Fridrich, 1994). Furthermore, neighborhood disorganization characterized by crime and publicly visible alcohol or drug use has been associated with adolescent substance use (Winstanley et al., 2008).

Executive functions are a wide array of behavioral and cognitive skills, which include attention, inhibition, flexibility, memory, self-monitoring, planning, and emotional control (Clark et al., 2017). These functions are a set of higher order thought processes used to navigate through our daily environment in order to achieve goals and maximize reward opportunities (Clark et al., 2017; Schroeder 
EXECUTIVE FUNCTIONS, RELATIONSHIPS, AND CIGARETTES

\& Kelley, 2010). Executive functions may serve to protect adolescents from choosing to consume a substance associated with reward seeking behaviors (Pentz \& Riggs, 2013). Deficits (or delays) in neuromaturation may by characterized by behaviors expressing executive dysfunction.

Attributes reflecting executive dysfunction have previously been associated with an increased risk of developing substance use disorders (Clark \& Winters, 2002). Past research has found executive dysfunction to be associated with binge drinking, frequency of alcohol use, marijuana use, and risk factors for developing alcohol use disorder (Clark et al., 2017). To examine executive dysfunction, these studies (as well as the present one) have used a multidimensional comprehensive measure of executive dysfunction, the Behavior Rating Inventory of Executive Function (BRIEF-2; (Baron, 2000; Gioia et al., 2002a,b; Guy et al., 2004; Roth et al., 2015).

Distant parental relationships including low monitoring and support have been associated with substance use (Gerra et al., 2004; Kaynak et al., 2013). Parental relationships consist of attributes including support, monitoring, decision influence, and communication. A study from 1253 college students found that lower levels of parental monitoring and decision influence during high school predicted an increased risk for developing alcohol use disorder during the first year of college (Kaynak et al., 2013). High levels of support and open communication have also been associated with lower levels of substance use (Wills \& Cleary, 1996; Kafka \& London, 1991). Social economic status may also influence parental relationships with variations in stress inducing conditions experienced by both the parents and children between families of different social economic status (Bradley \& Corwyn, 2002).

Characteristics of parental relationships have been shown to predict elements of healthy executive functioning in children and adolescents. Strong levels of parental support have been associated with improvements in a child's organization/planning, working memory, and inhibition 
EXECUTIVE FUNCTIONS, RELATIONSHIPS, AND CIGARETTES

(Schroeder \& Kelley, 2010). In contrast, environmental stressors, abuse, and trauma experienced by children and adolescents has been directly associated with disruptions in the development of the PFC and other brain regions that may regulate executive functions (De Bellis \& A.B., 2014; Schroeder \& Kelley, 2010). Parental warmth, positive parenting, support and expressivity are significantly correlated with improvements in behavioral regulation, emotional regulation, and attention control (Schroeder \& Kelley, 2010). Childhood socioeconomic status has also been found to predict executive functions in adolescents. Furthermore, social economic status may influence both parental relationships and adolescent executive functioning (Hackman, Gallop, Evans, \& Farah, 2015).

The goal of this study was to determine the relationships between adolescent executive dysfunction in daily life measured by the Behavior Rating Inventory of Executive Function (BRIEF-2), distant parental relationships, and cigarette use in youth between the ages of $12-18$. These relationships were examined using subjects in the National Consortium on Alcohol and Neurodevelopment in Adolescents (NCANDA) at the initial (and third) follow up assessment. NCANDA seeks to examine developmental risk factors of alcohol use and their outcomes in adolescent populations through a longitudinal design (Sandra A. Brown et al., 2015).

With the evidence of past research, it is hypothesized that executive dysfunction and distant parental relationships will predict cigarette use and the number of cigarettes adolescents choose to consume. Furthermore, it is hypothesized that both executive functions and parental relationships will mediate this relationship. Multivariate models were used to construct the latent variables and to explore their interactions. Bivariate relationships were used to assess correlations and the demographic characteristics of each measure; covariates in the model included age, race, sex, and access to drugs. Odds ratios were used to construct an average profile in the model and were then converted into 
EXECUTIVE FUNCTIONS, RELATIONSHIPS, AND CIGARETTES

probability scores for low and high levels of parental relationships and executive functions considering age, sex, and access to drugs.

\section{Method}

\section{Participants}

The participants ( $n=503$; age $12-18$ ) were subjects in the NCANDA study ( $n=817$; age $12-21$ ). Subjects were recruited by NCANDA from five locations across the United States including: Duke University, University of Pittsburgh, Oregon Health \& Science University, University of California, San Diego, and SRI International.

\section{Subjects}

The NCANDA study used a longitudinal design across five annual timepoints (waves), sampling subjects from a wide variety of ages to record development during this critical phase of adolescence. The exclusion criteria for the NCANDA study included not being between the ages of $12.0-21.9$ years old, no parental consent, factors that precluded valid participation, early developmental problems, major psychiatric disorders, medications, serious medical problems, and excessive substance use. The exclusion criteria for this study consisted of being over the age of 18 at wave 1, having an incomplete data set, or exceeding substance use thresholds.

The demographics of the population were as follows: age: $(M=16.2$ years, $S D=2.5)$ range: 12.0 17.9; female: $n=254$, male: $n=250$; ethnicity: Hispanic: $n=59$ (11.7\%), non-Hispanic $n=437(86.7 \%)$; race: Caucasian: $n=382$ (75.8\%), African American $n=60$ (11.9\%), Asian Caucasian $n=17$ (3.4\%), Asian $\mathrm{n}=31(6.2 \%)$, Native American $\mathrm{n}=3(<1 \%)$, Pacific Islander $\mathrm{n}=1(<1 \%)$. The ethnicity and race 
EXECUTIVE FUNCTIONS, RELATIONSHIPS, AND CIGARETTES

proportions represented in these samples are similar to the demographics of the U.S. population (Brown et al., 2015).

In the sample, most participants $(n=451)$ did not consume any cigarettes while a small group ( $\mathrm{n}$ = 53) reported smoking at least one cigarette in the past 365 days (see table 1). The average BRIEF-2 GEC score for nonsmokers $(M=49.9, S D=9.8)$ was lower than that of smokers $(M=55, S D=12.1)$, suggesting smokers expressed on average greater executive dysfunction. The average parental relationship raw score was higher for nonsmokers $(M=62.7, S D=8.8)$ compared to smokers $(M=57.2$, $S D=8.1$, suggesting on average smokers had a greater distance in their parental relationship.

Furthermore, those who smoked cigarettes $(M=11.7, S D=2.9)$ reported higher neighborhood access to (all types) drugs than subjects who did not smoke cigarettes $(M=10.53, S D=5)$.

Youth exposed to increased risk for substance use such as family substance use disorder history, disruptive behavior disorder, or two or more anxiety or depression symptoms made up about (50\%) of the NCANDA population. In the sample $(n=105,20.2 \%)$, reported a high access to substances, $(n=252$, $51.3 \%)$ reported moderate access to substance, and $(n=134,27.2 \%)$ reported low access to substances. Minors provided assent (with legal guardian consent) to the NCANDA study.

\section{Measures}

\section{Behavior Rating Inventory of Executive Function - Version 2}

The BRIEF-2 Self Report Form (Baron, 2000; Gioia et al., 2002a,b; Guy et al., 2004; Roth et al., 2015) is a 80-item self-report behavioral rating scale of problem solving, purposeful, and goal directed behavior with higher scores associated with executive dysfunction; this measure was taken from wave 1. The survey asked for each question, "Over the past 6 months, how often has each of the following behaviors been a problem?" allowing the participant to respond with either "often", 2 "sometimes", or 1 
EXECUTIVE FUNCTIONS, RELATIONSHIPS, AND CIGARETTES

"never". The questionnaire measures 7 factors including: Inhibition, Self-Monitor, Behavioral Shift, Emotional Control, Task Completion, Working Memory, and Planning/Organization.

Inhibition (8 items): "I am impulsive (I don't think before doing)," "I have problems waiting my turn," "I get out of control more than my friends".

Self-Monitor (5 items): "I am not aware of how my behavior affects or bothers others," "I don't notice when my behavior causes negative reactions until it is too late", "I have a poor understanding of my own strengths and weaknesses (I try things that are too difficult or too easy for me)."

Behavioral Shift (8 items): "I have trouble changing from one activity to another," "I have trouble getting used to new situations (such as classes, groups, or friends)";

Emotional Control (6 items): "I get upset over small events", "I have angry outbursts", "I overreact," "My eyes fill with tears quickly over little things".

Task Completion (7 items) "I have problems completing my work," "I have problems finishing long-term projects (such as papers or book reports)".

Working Memory (8 items): "When I am given three things to do, I remember only the first or last," "I have trouble remembering things, even for a few minutes (such as directions or phone numbers)".

Planning/Organization (10 items) "I have trouble prioritizing (ordering) my activities," "I get caught up in details and miss the main idea" "I have trouble carrying out the things that are needed to reach a goal, such as saving money for special needs, studying to get good grades, etc". 
EXECUTIVE FUNCTIONS, RELATIONSHIPS, AND CIGARETTES

The 7 factors then load into 3 indexes: the Behavior Regulation Index (BRI; Inhibition and SelfMonitor), the Emotion Regulation Index (ERI; Behavioral Shift and Emotional Control), and the Cognitive Regulation Index (CRI; Task Completion, Working Memory, Planning/Organization); the summary of these three indexes forms the Global Executive Composite score (GEC). Furthermore, the survey uses two validity scales, such as an inconsistency scale comparing the answers to 10 questions to confirm the participant responded consistently; and a 10-item negativity scale that determined if the participant was abnormally critical of their behaviors.

Raw scores were used to calculate t-scores, with scores below 59 considered normal, 60 to 64 mildly elevated, 65 to 69 potentially clinically elevated, and 70 or above considered clinically elevated. Subjects with invalid and missing responses $(n=36)$ were excluded from all analyses.

\section{Parental Warmth, Monitoring, Knowledge, Control \& Relationship Scale}

The Parental Warmth, Monitoring, Knowledge, Control \& Relationship Scale (Parental Relationship Scale), adapted from Stattin \& Kerr (2000), is a 26-item self-report scale filled out by the adolescent and is used to determine their relationship with their parents; this measure was taken from wave 1. The survey measures five factors including: Parental Support, Monitoring "Attempted", Monitoring "Actual”, Decision Influence, and Communication.

Parental support (6 items): "I can count on my father/mother to help me out, if I have some kind of problem" allowing the participants to respond with 4 "always", 3 "usually", 2 "sometimes, or 1 "never".

Parental decision influence (6 items): "How do you make the following decision: Which friends I spend time with" How do you make the following decision: Whether or not I can drink alcohol", was 
EXECUTIVE FUNCTIONS, RELATIONSHIPS, AND CIGARETTES

reported on a scale of 1-5 including: 1 "I decide this without discussing it with my parents", 2 "I make the final decision after discussing it with my parents", 3 "my parents and I decide together", 4 "my parents make the final decision after discussing it with me", and 5 "my parents decide for me" .

Parental communication (4 items): "Do your parent(s) know who you are with when you are away from home", "when you are out, do your parent(s) know what time you will be back" was assessed on a scale of 1-3 including: 3 "almost always," 2 "sometimes", and 1 "almost never".

Parental monitoring was broken down into two separate inventories consisting of "attempted parental monitoring" or how well parents attempted or "tried" to monitor their children and "actual parental monitoring" or how well parents actually or "really" monitor their children. The inventories asked for each question how the parent(s) either try or actually monitor an adolescent's decision.

Attempted Parental Monitoring: (5 items): "What you do with your free time," "who your friends are" allowing the subjects to respond with, 1 "don't try to know", 2 "sometimes try to know", and 3 "try a lot to know". Actual Parental Monitoring (5 items): "what you do with your free time", "who your friends are" was assessed on a scale of 1-3 incldung: 3 "always really know", "sometimes really know", and "Don't really know".

\section{Neighborhood Access to Substances Questionnaire - Adolescent}

The Neighborhood Access to Substances Questionnaire (Adolescent Version; Komro, Maldonado-Molina, Tobler, Bonds, \& Muller, 2007; Tobler, Komro, \& Maldonado-Molina, 2009) is a 17item measure filled out by the adolescent and is used to gauge how difficult it would be to acquire substances in their household, neighborhood, or from anywhere; this measure was taken at wave 3 . The survey asked for each question "how easy would it be to get drugs from..." and provided prompts such 
EXECUTIVE FUNCTIONS, RELATIONSHIPS, AND CIGARETTES

as "a place in your neighborhood", "your home", or "anywhere." The participants could respond with 1 "very difficult", 2 "fairly difficult, 3 "fairly easy," "4 "very easy", 5 "don't know".

\section{Customary Drinking and Drug Use Record}

The Customary Drinking and Drug Use Record (CDDR) was used to record cigarette use in the past 365 days (Brown et al., 1998); this measure was taken at wave 3. This study used CDDR question \#5 "how many cigarettes have you smoked in the last year, so out of 365 days" to assess both binary and total cigarettes used in the past year. To help the subject recall the number of cigarettes they smoked in the past year, the interviewer would issue prompts such as "on average how many cigarettes have you been smoking per day" and "for how long?" For binary scoring of cigarette use, any number of cigarettes used in the past 365 days was coded as 1 for "smoked a cigarette in the past 365 days"; those who did not report smoking any cigarettes in the past year were coded as 0 for "did not smoke a cigarette in the past 365 days".

\section{Design}

Using the NCANDA data, this study examined independent variables that may predict substance use. The targeted independent variables were parental relationships from the Parental Relationship Scale and executive functions from the BRIEF-2 GEC. The dependent variables were cigarette use and total number of cigarettes smoked in the past 365 days, as reported from the Customary Drinking and Drug Use Record (S. A. Brown et al., 1998).

Parental relationships were determined from the Parental Relationship Scale's (Stattin \& Kerr 2000) subcategories, including Parental Support, Attempted Monitoring, Actual Monitoring, Decision Influence, and Communication. Executive functions were determined from the BRIEF-2 GEC (Baron, 2000; Gioia et al., 2002a,b; Guy et al., 2004; Roth et al., 2015), including indexes of behavioral, 
EXECUTIVE FUNCTIONS, RELATIONSHIPS, AND CIGARETTES

emotional, and cognitive regulation. Age, race, and sex were taken from a demographic interview. Access to substances was determined by the Neighborhood Access Questionnaire adapted from Komro et al. (2007) and Tobler et al. (2009). All variables were taken from wave 1 other than cigarette use and access to substances which was taken from wave 3.

\section{Analysis}

An exploratory factor analysis was used to uncover the underlying structure of the relationships between the observed wave 1 variables (see figure 1; EFA: factor 1: global executive composite; $32 \%$ of variance, factor 2: parental relationship; $18.5 \%$ of variance). A confirmatory factor analysis was then used to construct the latent variables: global executive composite from the BRIEF-2 GEC and parental relationships from the Parental Relationship Scale. The multivariate model fit the adolescent selfreported data adequately (see figure 2; CFA: RSMEA: 0.039, CFI: 0.989, TLI: 0.984).

A multivariate longitudinal mediation analysis with a binary outcome variable (cigarette use) was used to test the mediation and prediction hypotheses (see figure 3; Model 1: wave 1 parental relationship, predicting wave 3 binary cigarette use, mediated by wave 1 global executive composite; see figure 4; Model 2: global wave 1 executive composite, predicting wave 3 binary cigarette use mediated by wave 1 parental relationship). Variables with significant relationships to predictor or outcome variables in the model were added as covariates. To study these interactions, a series of Hayes' Process Models (Model 4) were run to test the set of hypotheses. In each case, a 5,000-percentile bootstrapped set of samples were used to calculate the average standard error and the indirect effect.

Coefficients from model 1 were used to construct log odd ratios of an average profile in the model. The log odd ratios were then converted into probability scores for age, parental relationships, 
EXECUTIVE FUNCTIONS, RELATIONSHIPS, AND CIGARETTES

and global executive composite (see table 2). Both models $1 \& 2$ were also run with total cigarette use as the outcome variable in place of binary cigarette use.

Although originally considered, a temporal mediation model was not a valid design for this study as wave 1 latent variables were highly correlated with their corresponding wave 2 variables (BRIEF-2 GEC: $r(504)=0.704, p<0.001 ;$ parental relationship: $r(504)=0.701, p<0.001$.

\section{Results}

\section{Bivariate Models}

\section{BRIEF-2 Description and Demographic Characteristics}

For all subjects with valid BRIEF-2 data, the average of the t-scores for Global Executive Composite were in the expected range based off prior studies with this sample population $(M=50.6, S D$ = 10.2; Clark et at., 2017). The regulation indexes were also in this range BRIEF-2; Emotional Regulation Index: $(M=50.4, S D 10.1)$, Cognitive Regulation Index: $(M=50.6, S D=10.1)$, and Behavioral Regulation Index: $(M=50.6, S D$ 10.5).

BRIEF-2 Global Executive Composite Scores did not significantly differ by gender (see figure 6; Global Executive Composite: Females: $M=51.0, S D=10.5$; Males: $M=50.2, S D=10 ; t(501)=0.880, p=$ 0.379). BRIEF-2 GEC was not significantly associated with race $F(9,494=0.511, p=0.876)$. Age and access to drugs were significantly correlated with BRIEF-2 GEC respectively $r(504)=0.099, p=0.026$ and $r(504)=0.092, p=0.041$. Ethnicity (Hispanic or non-Hispanic) was also significantly associated with BRIEF-2 GEC $t(494)=-3.646, p<0.001$.

Parental relationships were found to be significantly correlated with BRIEF-2 GEC $r(504)=-$ $0.221, p<0.001$ so that a more distant parental relationship was associated with more executive 
EXECUTIVE FUNCTIONS, RELATIONSHIPS, AND CIGARETTES

dysfunction. BRIEF-2 GEC was found to be significantly correlated with Parental Relationship Scale's indexes including: Support $r(504)=-0.278 p<0.001$, Monitoring "Attempted" $r(504)=-0.129, p<0.001$, Monitoring "Actual" $r(504)=-0.233, p<0.001$, and Communication $r(504)=0.199, p<0.001$.

\section{Parental Relationship Scale Description and Demographic Characteristics}

For subjects with valid Parental Relationship Scale data, the mean of the raw scores was $(M=$ $62.1, S D=8.9$ ). The parental relationship scores did not differ by gender (see figure 7; female: $M=62.2$, $S D=9.3$, male $M=62.1, S D=8.4 ; t(502)=0.053, p=0.958)$. Race was not significantly associated with parental relationship scores $F(9,494)=0.272, p=0.982$. Age $r(504)=-0.325, p<0.001$, and access to drugs $r(504)=-0.110, p=0.015$ were significantly correlated with parental relationship scores. Ethnicity was significantly associated with parental relationship scores $t(494)=2.109, p=0.035$. Parental relationships were also correlated with BRIEF-2 GEC $r(504)=-0.221, p<0.001$ and significantly associated with the BRIEF-2 indexes including: Behavioral Regulation $r(504)=-0.197, p<0.001$, Emotional Regulation $r(504)=-0.178, p<0.001$, and Cognitive Regulation $r(504)=-0.219, p<0.001$.

\section{Cigarette Use Description and Demographic Characteristics}

Past year cigarette use was present in 53 subjects (table 1). Cigarette use was significantly related to BRIEF-2 GEC $t(502)=-4.054, p<0.001$, with the presence of executive dysfunction associated with cigarette use. Cigarette use was associated with more adolescent self-reported issues on BRIEF-2 Behavioral Regulation Index $t(502)=-3.644, p<0.001$, Cognitive Regulation Index $t(502)=-4.261, p<$ 0.001 ), and Emotional Regulation Index $t(63)=-2.535, p=0.014$. This effect remained constant throughout a majority of the sub-scales including: Inhibition $t(503)=-3.583, p<0.001$, Self-Monitor $t(62)=-2.638, p=0.011$, Emotional Control, $t(61)=-2.828, p=0.006$, Task-Completion $t(502)=-3.097, p$ 
EXECUTIVE FUNCTIONS, RELATIONSHIPS, AND CIGARETTES

$<0.001$, Working Memory $t(502)=-3.724, p<0.001$, and Planning/Organization $t(61)=-3.668, p=$ 0.001 .

Cigarette use was significantly related the Parental Relationship Scale raw scores $t(67)=4.609, p$ $<0.001$, with distant parental relationships associated with cigarette use. Cigarette use was associated with greater adolescence self-reported distance for subscales including: Parental Support $t(66)=2.165$, $p=0.034$ Monitoring "Actual" $t(64)=4.372, p<0.001$, Decision Influence $F(502)=5.269, p<0.001$, and Communication $F(65)=-5.210, p<0.001$.

Cigarette use was more common among males $(n=34)$ than females $(n=19)$. Cigarette use was not associated with race $F(9,494)=1.082, p=0.375$, ethnicity $t(62)=-0.349, p=0.728$, or access to drugs $t(490)=-1.604, p=0.109$. Cigarette use was significantly associated with age $t(502)=-4.738, p<$ 0.001 such that older subjects had a greater likelihood of smoking.

Total cigarettes smoked in the past year was found to not be significantly correlated with BRIEF2 GEC, age, access to drugs, race, and ethnicity. Distant parental relationships were found to be significantly associated with total cigarettes smoked in the past year $r(504)=-0.156, p<0.001$. Race was removed as a covariate as it did not significantly correlate with any other variables in the model.

\section{Multivariate Longitudinal Mediation Analysis}

\section{Model 1}

A multivariate longitudinal mediation analysis with a binary outcome variable (cigarette use) was used to test model 1 (see figure 3) consisting of wave 1 parental relationship, predicting wave 3 binary cigarette use, mediated by wave 1 global executive composite $\left(\beta_{\text {indirect }}=-0.01, \mathrm{Cl}:-0.02,-0.003\right.$; $\beta_{\text {direct }}=-0.05, p=0.007$, total effect: -0.06$)$. All paths in the model were found to be significant 
EXECUTIVE FUNCTIONS, RELATIONSHIPS, AND CIGARETTES

suggesting partial mediation has occurred (see table 5 ). The parental relationship model (see table 3 ) was found to account for (22\%) of the variance in BRIEF-2 GEC (parental relationships predicting executive functions; $\beta=-0.23, p<0.001$ ). In the binary cigarette use model (see table 5 ) parental relationships were found to predict cigarette use $(\beta=-0.049$, odds $=0.952 p=0.007)$. BRIEF-2 GEC $(\beta=$ 0.046$, odds $=1.047, p=0.002)$, age $(\beta=0.353$, odds $=1.424, p=0.001)$, and $\operatorname{sex}(\beta=-0.729$, odds $=$ $0.483, p=0.024)$ were also found to predict cigarette use. Access to drugs $(\beta=0.0315$, odds $=1.032 p=$ 0.363 ) was not found to predict cigarette use.

\section{Model 2}

The same analysis was used to test model 2 (see figure 4) consisting of the same logistic regression paths as model one in a different predictive order (Model 2: global wave 1 executive composite, predicting wave 3 binary cigarette use mediated by wave 1 parental relationship; $\beta_{\text {indirect }}=$ 0.008: $\mathrm{Cl}: 0.002,0.02 ; \beta_{\text {direct }}=0.05, p=0.002 ;$ total effect $=0.05$ ). The executive functions model (see table 4) was found to account for (37\%) of the variance in parental relationships (executive functions predicting parental relationships; $\beta=-0.15, p<0.001$ ). Therefore, all logistic regression paths in the model were found to be significant with the same coefficients and significance also suggesting partial mediation has occurred in this model.

\section{Total Cigarettes Smoked in the Past 365 Days}

In both models 1 and 2, binary cigarette use was replaced with the total amount of cigarettes smoked in the past year. The total cigarette use model (see table 6) was found to account for (19\%) of the variance in the total number of cigarettes smoked in the past 365 days. BRIEF-2 GEC did not predict total cigarettes used in the past year $(\beta=0.52, p=0.651)$. Parental relationships $(\beta=-5.27, p<0.001)$ and age $(\beta=-14.38, p=0.04)$ were found to predict total cigarettes used in the past year. Access to 
EXECUTIVE FUNCTIONS, RELATIONSHIPS, AND CIGARETTES

drugs $(\beta=1.62, p=0.494)$ and $\operatorname{sex}(\beta=-22.83, p=0.3152)$ were not found to predict total cigarettes used in the past year. There was a significant indirect effect $\left(\beta_{\text {indirect }}=0.8112, \mathrm{Cl}: 0.02,2.33\right)$ between BRIEF-2 GEC and total cigarettes smoked in the past 365 days mediated by parental relationships. The indirect effect between parental relationships and total number of cigarettes smoked in the past 365 days mediated by executive functions was found not to be significant $\left(\beta_{\text {indirect }}=-0.1174, \mathrm{Cl}:-0.72,0.46\right)$.

\section{Odds Ratio for Model 1 Coefficients}

Given the model results, odds ratios were utilized to examine representative profiles based on the coefficients for model 1. Each profile represents an average level of executive functioning, parental relationship, access to drugs, and age based on the sample population. The odds ratios were then converted to probability values and thus a percentage for each interaction (see table 2). A female in the sample with an average level of executive functioning, parental relationship, access to drugs, and age had a (4.9\%) probability of being a cigarette smoker, while an average male in the sample had a (9.7\%) probability.

The oldest participant in the sample was 17.9 years old; the oldest female in the sample with an average level of executive functioning, parental relationship, and access to drugs had a (12.9\%) probability of smoking, while the oldest male had a (23.6\%) probability of smoking (see figure 8 ). The average age of the participants in the sample was 15 years old. A 15-year-old female with a distant parental relationship, and an average level of executive functioning and access to drugs had a (17.1\%) probability of being a smoker, while an average 15-year-old male with a distant parental relationship had a (29.91\%) probability of smoking. A 15-year-old female with a low level of executive functioning, and an average parental relationship and access to drugs had a (19.6\%) chance of smoking cigarettes, 
EXECUTIVE FUNCTIONS, RELATIONSHIPS, AND CIGARETTES

while an average 15-year-old male expressing a low level of executive functioning had a (33.6\%) chance of smoking cigarettes.

\section{Discussion}

The results obtained from this study complements past research involving substance use, parental relationships, and BRIEF-2 GEC. Subsequent studies (to NCANDA) have found similar normative sample BRIEF-2 GEC t-scores to the NCANDA population (Roth et al., 2015). BRIEF-2 GEC and parental relationships were not related to race or gender, but showed a significant relationship to age, ethnicity, and access to drugs. Past research suggests that social economic status substantially accounts for ethnicities significance in this relationship. We also draw from this result that neighborhoods or households with high access to drugs may have higher levels of "unhealthy" role models which impact an adolescent's ability to problem solve or use purposeful and goal directed behavior.

Past research has also observed this effect suggesting that adolescents exposed to negative adult role model behaviors, such as substance use, is associated with attributes of executive dysfunction including internalizing and externalizing behaviors and adolescent substance use (Hurd, Zimmerman, \& Xue, 2009). A survey given to $82,9187^{\text {th }}$ graders in the United States found adolescents with the highest levels of drug use were associated with subjects that were not educated about the consequences of drugs (education was most commonly provided by the parents; Kelly, Comello, \& Hunn, 2002).

As expected, distant parental relationships and executive dysfunction has been found to predict cigarette use in adolescents between the ages of 12-18. As expected, higher BRIEF-2 GEC (associated with executive dysfunction) and a lower parental relationship score (associated with a distant parental relationship) were significantly correlated with cigarette use (see figure 5). We suggest from this finding that as distant parental relationships increase with age, parental decision influence, communication, 
EXECUTIVE FUNCTIONS, RELATIONSHIPS, AND CIGARETTES

monitoring, and support decreases, which then increases the likelihood that an adolescent will choose to smoke cigarettes. Furthermore, attempted parental monitoring (such as a parent asking a child about their plans) has less of an impact on cigarette consumption compared to actual parental monitoring (such as the child truthfully telling the parent their plans).

The results indicated that parental decision influence, communication, actual monitoring, and support had the biggest impact on cigarette use. We draw from this result that a greater distance in the relationship between an adolescent and their parent, expressed by lower levels of parental decision influence, communication, monitoring, and support increases the likelihood that an adolescent will choose to consume cigarettes. This finding complements past research, suggesting that inadequate parental monitoring (Barnes \& Farrell, 1992; Biglan, Duncan, Ary, \& Smolkowski, 1995; Stice, Barrera, \& Chassin, 1993), support (Barnes \& Farrell, 1992; Stice et al., 1993), decision influence (Becoña et al., 2012; Stice et al., 1993), and communication (Kelly et al., 2002) is associated with an increased risk of adolescent substance use.

However, parental relationships may be restricted by other variables such as socioeconomic status which has been found to have a significant influence over parental relationships (Bradley \& Corwyn, 2002). Family income, parental education, and occupational status have been associated with a wide variety of health, cognitive, and socioemotional outcomes in children, with effects of early social economic status remaining constant through adolescence and into adulthood (Bradley \& Corwyn, 2002).

Increasing factors of parental support, monitoring, decision influence, and communication will decrease the distance in a parental relationship and the probability that an adolescent will choose to consume cigarettes. Although, a relationship with an emotional overinvolvement could produce negative outcomes, as excessive decision influence and monitoring could potentially inhibit social 


\section{EXECUTIVE FUNCTIONS, RELATIONSHIPS, AND CIGARETTES}

development (Stice, Barrera, \& Chassin, 1993). The relationship between executive functions and parental relationships may be quadratic rather than linear; future studies should explore this interaction further.

The implications of a quadratic relationship would suggest that increasing the proximity of the parental relationship would provide the best outcome for adolescents who have already elected to consume cigarettes rather than those who are not smoking. If the parent(s) have a healthy relationship with their child, the relationship will likely transfer better role modeling and thus reduce externalizing (Stice, Barrera, \& Chassin, 1993) and internalizing (Rankin Williams et al., 2009; Stice, Barrera, \& Chassin, 1993) behaviors associated with improvements in executive functioning (Hurd et al., 2009).

Considering both models, it was not apparent which variable (global executive composite or parental relationship) was acting as the primary partial-mediator. The model fit, total effect, indirect effect, and direct effect were nearly identical in each model. However, parental support, monitoring, decision influence, and communication were all found to predict executive functions while emotional control was the only element of executive functions found to predict parental relationships. This suggests that parental relationships are likely better to predict executive functions compared to executive functions predicting parental relationships. Future studies should explore this relationship further.

Executive functions and parental relationships both act as partial mediators in this relationship; we suggest from this finding that the lack of guidance that occurs in distant parental relationships promotes executive dysfunction. However, in a healthy relationship, parents may allot more attention towards guiding their child if they feel as if they are not functioning adequately. Closing the distance of a parental relationship by increasing, monitoring, communication, and decision influence would support 
EXECUTIVE FUNCTIONS, RELATIONSHIPS, AND CIGARETTES

the transference of behavioral guidance to a child expressing executive dysfunction (Rankin Williams et al., 2009).

Past studies have found significant correlations between executive dysfunction and substance use such as alcohol use, binge drinking, and marijuana use (Pentz \& Riggs, 2013; Familiar et al., 2015; Long et al., 2015; Clark et al., 2017). The results from this study indicate executive dysfunction is also significantly correlated with cigarette use, suggesting similar underlying mechanisms. Executive functions are associated with substance use disorder risk indicators, including internalizing and externalizing characteristics (Familiar et al., 2015; Long et al., 2015), the early onset of substance use (Tarter et al., 2003), and familial risk factors (Tapert and Brown, 2000). As observed with other substances, these attributes are associated with executive function's influence on cigarette use in adolescent populations.

Studies have also found a correlation between social economic status and executive functioning in adolescents (Hackman et al., 2015). Early disparities associated with accumulated stressors from a family's social economic status are likely to impact a child's development trajectory. Persisting disparities related to social economic status explained by characteristics of the home and family environment may be a potential source of the significance in the relationship between executive functions and social economic status (Hackman et al., 2015). While this study sought to investigate the direct effects of parental relationships on executive functioning and cigarette use, future studies should explore the interaction of social economic status further.

Distant parental relationships were found to predict the number of cigarettes adolescents chose to smoke. Although, contrary to this study's hypothesis, executive dysfunction does not have the same influence. Attributes of executive dysfunction, including a lack of behavioral and emotional regulation, 
EXECUTIVE FUNCTIONS, RELATIONSHIPS, AND CIGARETTES

influence externalizing and internalizing characteristics which are known to be associated with the early onset of substance use (Tarter et al., 2003). However, the results in this study suggest, once an adolescent makes an executive choice to smoke cigarettes, other factors embedded into parental relationships such as monitoring, communication, and decision influence are significantly associated with the number of cigarettes they consume. Executive functions were also found to have a significant indirect influence on the total number of cigarettes smoked, through the mediation of parental relationships.

Whether or not an adolescent chooses to smoke, distance in the child-parent relationship has been found to increase with age (Keijsers \& Poulin, 2013). This provides a possible explanation as to why parental relationships were significantly associated with cigarette use. Age and sex have been found to be even greater predictors of cigarette use compared to distant parental relationships and executive dysfunction. Based on this finding, it is possible that even though executive functions and parental relationships both act as partial mediators in this relationship, the modest reduction in the relationship between parental relationships, executive functions, and cigarette use suggests the mediation hypotheses may not truly be supported.

Although not originally hypothesized in our model, we observed significant differences in the probability of smoking cigarettes between sexes. Average males were twice as likely to smoke cigarettes compared to average females, which was consistent with prior research (Becker \& Hu, 2008). This effect remained constant while considering age, parental relationships, and executive functions.

To explain this interaction, it is likely that sex differences such as observed in this study, are not influenced solely by biology or sociocultural factors, instead they represent interactions among biological, environmental, developmental, and sociocultural elements (Becker, McClellan, \& Reed, 
EXECUTIVE FUNCTIONS, RELATIONSHIPS, AND CIGARETTES

2017). Sex differences may not represent vulnerability to use but rather reflect differences in opportunities to use cigarettes (Becker \& Hu, 2008). However, future studies should explore the mechanisms of this interaction further.

The results from this study provides insight into some of the underlying mechanisms that predict cigarette use in adolescents. The implications of these results provide a framework to base targeted preventative interventions for cigarette use in adolescent populations. Preventative treatment interventions should consider social economic status and aim to close the distance in a child-parental relationship, by improving levels of parental support, actual monitoring, decision influence, and communication, which is also effective at reducing internalizing and externalizing behaviors associated with executive dysfunction and substance use.

Adolescents who express characteristics of executive dysfunction, especially those who are closer to 18 years old and have a distant parental relationship, should be a targeted population in these preventative interventions. Therapeutic interventions designed to decrease the distance in a parentchild's relationship would likely be more effective in preventing or reducing cigarette use compared to interventions designed to improve an adolescent's executive functioning.

These concepts could be applied to preventing an adolescent's initial cigarette use or to prevent or reduce further cigarette use. The successful outcome of treatments that target these underlying mechanisms may reduce the number of adolescents who continue to smoke into adulthood and thus prevent significant health complications associated with long term cigarette use. 


\section{References}

Barnes, G. M., \& Farrell, M. P. (1992). Parental Support and control as predictors of adolescent drinking, delinquency, and related problem behaviors. Journal of Marriage and Family, 54(4), 763-776. https://doi.org/10.2307/353159

Becker, J. B., \& Hu, M. (2008). Sex differences in drug abuse. Frontiers in Neuroendocrinology, 29(1), 3647. https://doi.org/10.1016/j.yfrne.2007.07.003

Becker, J. B., McClellan, M. L., \& Reed, B. G. (2017). Sex differences, gender and addiction. Journal of Neuroscience Research, 95(1-2), 136-147. https://doi.org/10.1002/jnr.23963

Becoña, E., Martínez, Ú., Calafat, A., Juan, M., Fernández-Hermida, J. R., \& Secades-Villa, R. (2012). Parental styles and drug use: A review. Drugs: Education, Prevention and Policy, 19(1), 1-10. https://doi.org/10.3109/09687637.2011.631060

Biglan, A., Duncan, T. E., Ary, D. V., \& Smolkowski, K. (1995). Peer and parental influences on adolescent tobacco use. Journal of Behavioral Medicine, 18(4), 315-330. https://doi.org/10.1007/BF01857657

Bonnie, R. J., Stratton, K., Kwan, L. Y., Products, C. on the P. H. I. of R. the M. A. for P. T., Practice, B. on P. H. and P. H., \& Medicine, I. of. (2015). patterns of tobacco use by adolescents and young adults. Retrieved from http://www.ncbi.nlm.nih.gov/books/NBK310407/

Bracken, B. K., Rodolico, J., \& Hill, K. P. (2013). Sex, age, and progression of drug use in adolescents admitted for substance use disorder treatment in the northeastern United States: Comparison with a national survey. Substance Abuse : Official Publication of the Association for Medical Education and Research in Substance Abuse, 34(3), 263-272. https://doi.org/10.1080/08897077.2013.770424

Bradley, R. H., \& Corwyn, R. F. (2002). Socioeconomic status and child development. Annual Review of Psychology, 53(1), 371-399. https://doi.org/10.1146/annurev.psych.53.100901.135233 
EXECUTIVE FUNCTIONS, RELATIONSHIPS, AND CIGARETTES

Brown, S. A., Brumback, T., Tomlinson, K., Cummins, K., Thompson, W. K., Nagel, B. J., ... Tapert, S. F. (2015). The National Consortium on Alcohol and NeuroDevelopment in Adolescence (NCANDA): a multisite study of adolescent development and substance use. Journal of Studies on Alcohol and Drugs, 76(6), 895-908. https://doi.org/10.15288/jsad.2015.76.895

Chen, P., \& Jacobson, K. C. (2012). Developmental trajectories of substance use from early adolescence to young adulthood: gender and racial/ethnic differences. Journal of Adolescent Health, 50(2), 154-163. https://doi.org/10.1016/j.jadohealth.2011.05.013

Clark, D. B., Chung, T., Martin, C. S., Hasler, B. P., Fitzgerald, D. H., Luna, B., ... Nagel, B. J. (2017). adolescent executive dysfunction in daily life: relationships to risks, brain structure and substance use. Frontiers in Behavioral Neuroscience, 11. https://doi.org/10.3389/fnbeh.2017.00223

Clark, D. B., \& Winters, K. C. (2002). Measuring risks and outcomes in substance use disorders prevention research. Journal of Consulting and Clinical Psychology, 70(6), 1207-1223. http://dx.doi.org.proxy.lib.pdx.edu/10.1037/0022-006X.70.6.1207

De Bellis, M. D., \& A.B., A. Z. (2014). The biological effects of childhood trauma. Child and Adolescent Psychiatric Clinics of North America, 23(2), 185-222. https://doi.org/10.1016/j.chc.2014.01.002

Flannery, D. J., Vazsonyi, A. T., Torquati, J., \& Fridrich, A. (1994). Ethnic and gender differences in risk for early adolescent substance use. Journal of Youth and Adolescence, 23(2), 195-213. https://doi.org/10.1007/BF01537445

Gamberino, W. C., \& Gold, M. S. (1999). Neurobiology of tobacco smoking and other addictive disorders. Psychiatric Clinics of North America, 22(2), 301-312. https://doi.org/10.1016/S0193$953 \times(05) 70078-2$

Gerra, G., Angioni, L., Zaimovic, A., Moi, G., Bussandri, M., Bertacca, S., ... Nicoli, M. A. (2004). Substance use among high-school students: relationships with temperament, personality traits, and 
EXECUTIVE FUNCTIONS, RELATIONSHIPS, AND CIGARETTES

parental care perception. Substance Use \& Misuse, 39(2), 345-367. https://doi.org/10.1081/JA120028493

Hackman, D. A., Gallop, R., Evans, G. W., \& Farah, M. J. (2015). Socioeconomic status and executive function: developmental trajectories and mediation. Developmental Science, 18(5), 686-702. https://doi.org/10.1111/desc.12246

Hurd, N. M., Zimmerman, M. A., \& Xue, Y. (2009). Negative adult influences and the protective effects of role models: A study with urban adolescents. Journal of Youth and Adolescence, 38(6), 777-789. https://doi.org/10.1007/s10964-008-9296-5

Jha, P., Ramasundarahettige, C., Landsman, V., Rostron, B., Thun, M., Anderson, R. N., ... Peto, R. (2013). 21st-century hazards of smoking and benefits of cessation in the united states. New England Journal of Medicine, 368(4), 341-350. https://doi.org/10.1056/NEJMsa1211128

Kafka, R. R., \& London, P. (1991). communication in relationships and adolescent substance use: the influence of parents and friends. Adolescence; Roslyn Heights, 26(103), 587-598.

Kaynak, Ö., Meyers, K., Caldeira, K. M., Vincent, K. B., Winters, K. C., \& Arria, A. M. (2013). Relationships among parental monitoring and sensation seeking on the development of substance use disorder among college students. Addictive Behaviors, 38(1), 1457-1463. https://doi.org/10.1016/j.addbeh.2012.08.003

Keijsers, L., \& Poulin, F. (2013). Developmental changes in parent-child communication throughout adolescence. Developmental Psychology, 49(12), 2301-2308. https://doi.org/10.1037/a0032217

Kelly, K. J., Comello, M. L. G., \& Hunn, L. C. P. (2002). Parent-child communication, perceived sanctions against drugs use, and youth drug involvement. Adolescence; Roslyn Heights, 37(148), 775-787.

Komro, K. A., Maldonado-Molina, M. M., Tobler, A. L., Bonds, J. R., \& Muller, K. E. (2007). Effects of home access and availability of alcohol on young adolescents' alcohol use. Addiction, 102(10), 1597-1608. https://doi.org/10.1111/j.1360-0443.2007.01941.x 
EXECUTIVE FUNCTIONS, RELATIONSHIPS, AND CIGARETTES

Pentz, M. A., \& Riggs, N. R. (2013). Longitudinal relationships of executive cognitive function and parent influence to child substance use and physical activity. Prevention Science, 14(3), 229-237. https://doi.org/10.1007/s11121-012-0312-3

Rankin Williams, L., Degnan, K. A., Perez-Edgar, K. E., Henderson, H. A., Rubin, K. H., Pine, D. S., ... Fox, N. A. (2009). Impact of behavioral inhibition and parenting style on internalizing and externalizing problems from early childhood through adolescence. Journal of Abnormal Child Psychology, 37(8), 1063-1075. https://doi.org/10.1007/s10802-009-9331-3

Schroeder, V. M., \& Kelley, M. L. (2010). Family environment and parent-child relationships as related to executive functioning in children. Early Child Development and Care, 180(10), 1285-1298. https://doi.org/10.1080/03004430902981512

Stattin, H., \& Kerr, M. (2000). Parental monitoring: a reinterpretation. Child Development, 71(4), 10721085. https://doi.org/10.1111/1467-8624.00210

Steinberg, L. (2008). A social neuroscience perspective on adolescent risk-taking. Developmental Review, 28(1), 78-106. https://doi.org/10.1016/j.dr.2007.08.002

Stice, E., Barrera, M., \& Chassin, L. (1993). Relation of parental support and control to adolescents' externalizing symptomatology and substance use: A longitudinal examination of curvilinear effects. Journal of Abnormal Child Psychology, 21(6), 609-629. https://doi.org/10.1007/BF00916446

Tobler, A. L., Komro, K. A., \& Maldonado-Molina, M. M. (2009). Relationship between neighborhood context, family management practices and alcohol use among urban, multi-ethnic, young adolescents. Prevention Science, 10(4), 313-324. https://doi.org/10.1007/s11121-009-0133-1

Warren, G. W., Alberg, A. J., Kraft, A. S., \& Cummings, K. M. (2014). The 2014 surgeon general's report: "the health consequences of smoking-50 years of progress": a paradigm shift in cancer care. Cancer, 120(13), 1914-1916. https://doi.org/10.1002/cncr.28695 
EXECUTIVE FUNCTIONS, RELATIONSHIPS, AND CIGARETTES

Wills, T. A., \& Cleary, S. D. (1996). How are social support effects mediated? A test with parental support and adolescent substance use. Journal of Personality and Social Psychology, 71(5), 937-952. http://dx.doi.org.proxy.lib.pdx.edu/10.1037/0022-3514.71.5.937

Winstanley, E. L., Steinwachs, D. M., Ensminger, M. E., Latkin, C. A., Stitzer, M. L., \& Olsen, Y. (2008). The association of self-reported neighborhood disorganization and social capital with adolescent alcohol and drug use, dependence, and access to treatment. Drug and Alcohol Dependence, 92(1), 173-182. https://doi.org/10.1016/j.drugalcdep.2007.07.012 
EXECUTIVE FUNCTIONS, RELATIONSHIPS, AND CIGARETTES

Tables

Table 1

Observed Variable Averages Between Cigarette Smokers and Non-Smokers

\begin{tabular}{|lcc|}
\hline Smoke & No (451) & Yes (53) \\
\hline & Mean (SD) & Mean (SD) \\
\hline Age & $14.87(1.71)^{* * *}$ & $16.03(1.39)^{* * *}$ \\
\hline Sex & $235 \mathrm{~F} / 216 \mathrm{M}$ & $19 \mathrm{~F} / 34 \mathrm{M}$ \\
\hline Access & $10.53(5)$ & $11.69(2.96)$ \\
\hline Parental Relationship & $62.71(8.77)^{* * *}$ & $57.23(8.13)^{* * *}$ \\
\hline Global Executive Composite & $49.96(9.82)^{* * *}$ & $55.89(12.04)^{* * *}$ \\
\hline
\end{tabular}

Notes: This table represents the sample demographics of participants in this study. ${ }^{A}$ Access to drugs (at wave 3), ${ }^{\mathrm{B}}$ Parental Relationships (at wave 1), ${ }^{\mathrm{C}}$ Global Executive Composite (at wave 1).

$* * * \mathrm{p}<0.001$ 
EXECUTIVE FUNCTIONS, RELATIONSHIPS, AND CIGARETTES

Table 2

Probability of Smoking Cigarettes in Model 1

\begin{tabular}{|lcccr|}
\hline \multicolumn{4}{|c|}{ Average Male } & \multicolumn{2}{c|}{ Average Female } \\
\hline \multicolumn{4}{|c|}{$9.68 \%$} & \multicolumn{2}{c|}{$4.92 \%$} \\
\hline Variable & High (Male) & Low (Male) & High (Female) & Low (Female) \\
\hline Age 12-18 & $23.61 \%$ & $3.59 \%$ & $12.98 \%$ & $1.77 \%$ \\
\hline Parental Relationships & $3.89 \%$ & $29.91 \%$ & $1.91 \%$ & $17.08 \%$ \\
\hline Executive Functions & $33.64 \%$ & $5.61 \%$ & $19.65 \%$ & $2.79 \%$ \\
\hline
\end{tabular}

Notes: Coefficients obtained from model 1 were used to construct odds ratios for an average profile in the model. The odds ratios were then converted to probability and thus a percentage for each interaction. 
EXECUTIVE FUNCTIONS, RELATIONSHIPS, AND CIGARETTES

Table 3

Parental Relationships Influence on Global Executive Composite: Considering Age, Sex, and Access to Drugs

\begin{tabular}{|lccr|}
\hline \multicolumn{4}{|l|}{ Outcome Variable: Global Executive Composite (Dysfunction) } \\
\hline & Coeff & S.E. & p-value \\
\hline constant & 61.388 & 6.2197 & $\mathbf{0 . 0 0 0 1}$ \\
\hline Parental Relationships & -0.2279 & 0.0542 & $\mathbf{0 . 0 0 0 1}$ \\
\hline Age & 0.1434 & 0.2781 & 0.6063 \\
\hline Sex & -0.7928 & 0.9026 & 0.3802 \\
\hline Access to Drugs & 0.1465 & 0.0941 & 0.1204 \\
\hline
\end{tabular}

Notes: Variables in the model explained (22.7\%) of the variance in global executive composite. Age, sex, and access to drugs were covariates in this model. 
EXECUTIVE FUNCTIONS, RELATIONSHIPS, AND CIGARETTES

Table 4

Global Executive Composite Influence on Parental Relationships: Considering Age, Sex, and Access to Drugs

\begin{tabular}{|lccr|}
\hline \multicolumn{2}{|l}{ Outcome Variable: Parental Relationships } & & \\
\hline & Coeff & S.E. & p-value \\
\hline Constant & 93.9028 & 3.6415 & $\mathbf{0 . 0 0 0 1}$ \\
\hline Executive Functions & -0.154 & 0.0366 & $\mathbf{0 . 0 0 0 1}$ \\
\hline Age & -1.5125 & 0.2182 & $\mathbf{0 . 0 0 0 1}$ \\
\hline Sex & -0.1625 & 0.7425 & 0.8268 \\
\hline Access to Drugs & -0.1133 & 0.0774 & 0.144 \\
\hline
\end{tabular}

Notes: Variables in the model explained (37.2\%) of the variance in parental relationships. Age, sex, and access to drugs were covariates in these models. 
EXECUTIVE FUNCTIONS, RELATIONSHIPS, AND CIGARETTES

Table 5

Global Executive Composite and Parental Relationships Influence on Binary Cigarette Use in the Past 365 Days: Considering Age, Sex, and Access to Drugs

\begin{tabular}{|lccr|}
\hline \multicolumn{4}{|l}{ Outcome Variable: Binary Cigarette Use in the Past 365 Days } \\
\hline & Coeff & S.E. & p-value \\
\hline Constant & -7.8768 & 2.4219 & $\mathbf{0 . 0 0 1 1}$ \\
\hline Parental Relationships & -0.0491 & 0.0182 & $\mathbf{0 . 0 0 7 1}$ \\
\hline Executive Functions & 0.0462 & 0.0149 & $\mathbf{0 . 0 0 1 9}$ \\
\hline Age & 0.3531 & 0.1051 & $\mathbf{0 . 0 0 0 8}$ \\
\hline Sex & 0.7286 & 0.3229 & $\mathbf{0 . 0 2 4 1}$ \\
\hline Access to Drugs & 0.0315 & 0.0346 & 0.3632 \\
\hline
\end{tabular}

Notes: A logistics regression analysis was used to code the binary variable cigarette use in the past 365 days ( 0 "no cigarette use in the past 365", 1 "cigarette use in the past 365"). The results are expressed in log-odds metric. 
EXECUTIVE FUNCTIONS, RELATIONSHIPS, AND CIGARETTES

Table 6

Global Executive Composite and Parental Relationships Influence on Total Number of Cigarettes Smoked in the Past 365 Days: Considering Age, Sex, and Access to Drugs

\begin{tabular}{|lccr|}
\hline \multicolumn{4}{|l|}{ Outcome Variable: Cigarettes Smoked in the Past 365 Days } \\
\hline \multicolumn{1}{|c}{ Coeff } & \multicolumn{1}{l|}{ S.E. } & p-value \\
\hline Constant & 530.6503 & 171.3254 & $\mathbf{0 . 0 0 2 1}$ \\
\hline Parental Relationships & -5.2693 & 1.3862 & $\mathbf{0 . 0 0 0 2}$ \\
\hline Executive Functions & 0.5154 & 1.1394 & 0.6512 \\
\hline Sex & -22.8382 & 22.7142 & 0.3152 \\
\hline Access to Drugs & 1.6239 & 2.3731 & 0.4941 \\
\hline Age & -14.3767 & 6.9957 & $\mathbf{0 . 0 4 0 4}$ \\
\hline
\end{tabular}

Notes: Variables in the model explained (19.1\%) of the variance in cigarette use in the past 365 days. Age, sex, and access to drugs were covariates in this model. 


\section{Exploratory Factor Analysis}

\begin{tabular}{|l|r|r|}
\hline \multicolumn{2}{|c|}{ Structure Matrix } \\
\hline & \multicolumn{2}{|c|}{ Factor } \\
\hline Sex & & 2 \\
\hline Age & & \\
\hline Parental Support & & .540 \\
\hline Parental Monitoring "Try" & & .560 \\
\hline Parental Monitoring "Acutal" & & .756 \\
\hline Parental Decision Influence & & .463 \\
\hline Parental Communication & & -.515 \\
\hline Behavior Regulation Index & .837 & \\
\hline Cognitive Regulation Index & .907 & \\
\hline Emotion Regulation Index & .864 & \\
\hline
\end{tabular}

Figure 1: Exploratory factor analysis: structure matrix for wave 1 observed variables. Factor 1: global executive composite from BRIEF-2 GEC; (32\%) of variance. Factor 2: parental relationships from Parental Relationship Scale; (18.5\%) of variance. Extraction Method: Principal Axis Factoring. Rotation Method: Promax with Kaiser Normalization. 


\section{Confirmatory Factor Analysis}

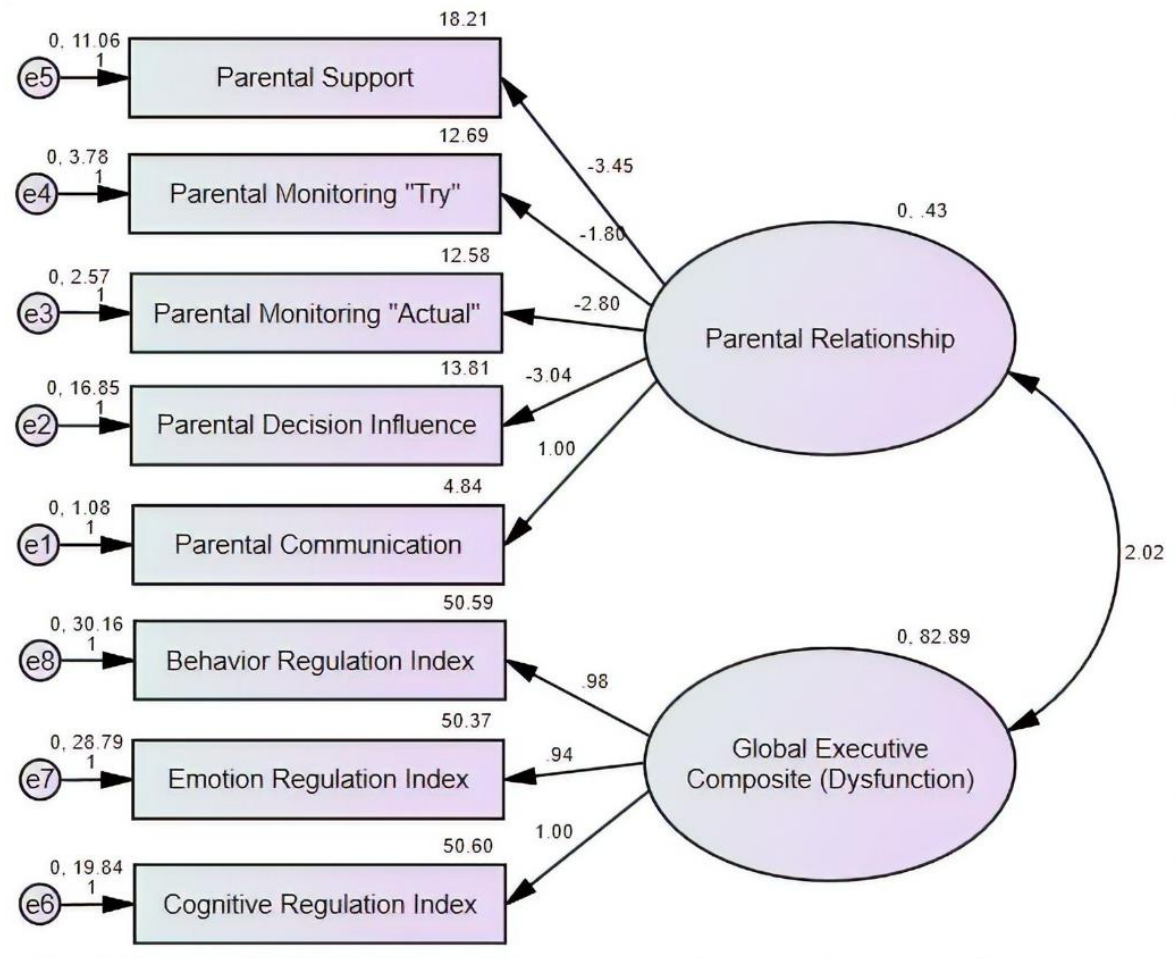

Figure 2: A confirmatory factor analysis was used to construct the latent variables: global executive composite from the BRIEF-2 GEC and parental relationships from the Parental Relationship Scale. The multivariate model fit the adolescent self-reported data adequately RSMEA: 0.039, CFI: 0.989, TLI: 0.984 . 
Model 1

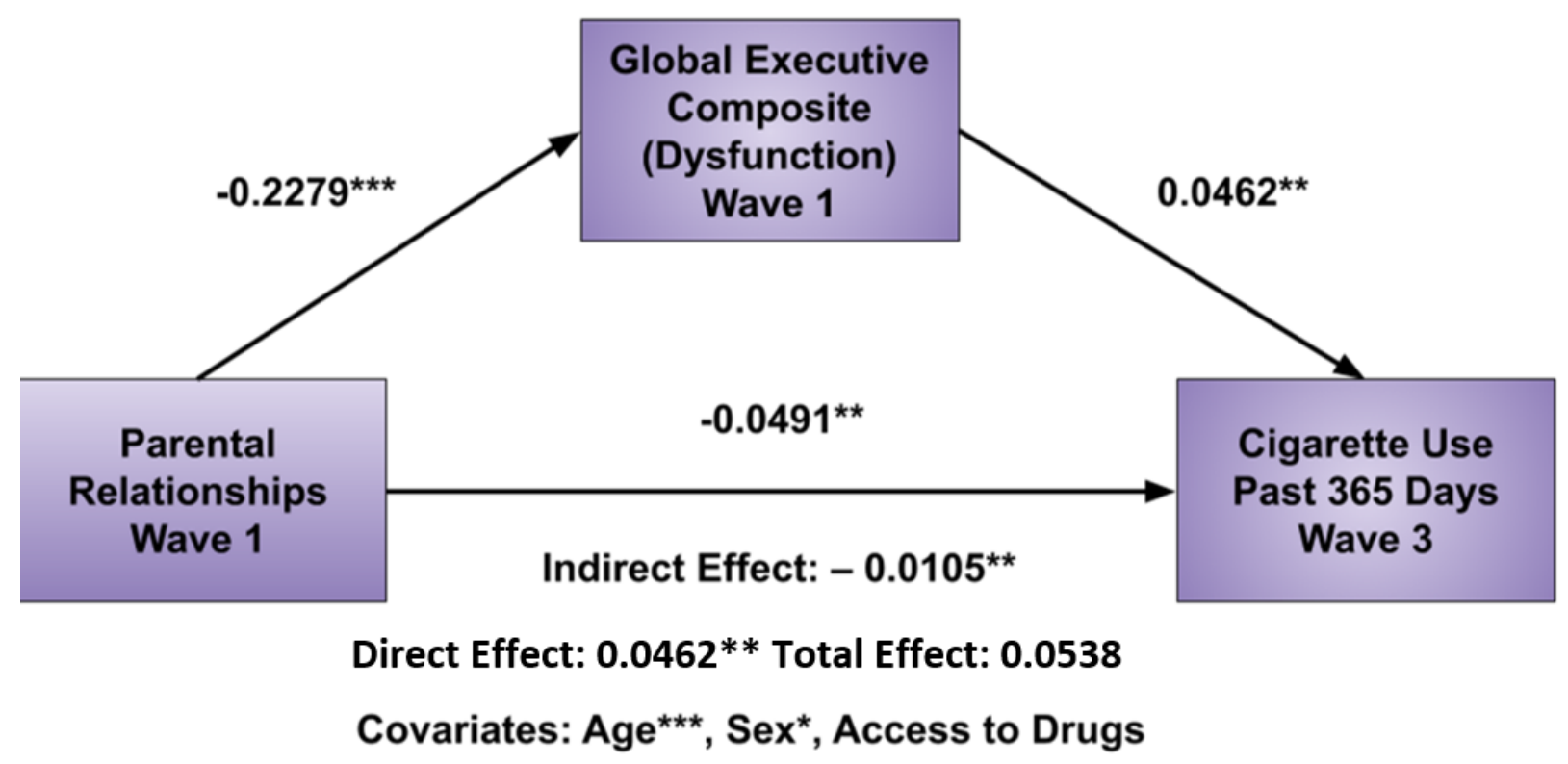

Figure 3: A multivariate longitudinal mediation model for the latent variable parental relationships (wave 1) from the Parental Relationship Scale, predicting binary cigarette use (wave 3) from the CDDR, mediated by the latent variable global executive composite (wave 1) from the BRIEF-2 GEC. All regression paths were found to be significant at the $p<0.01$ level of confidence. 
Model 2

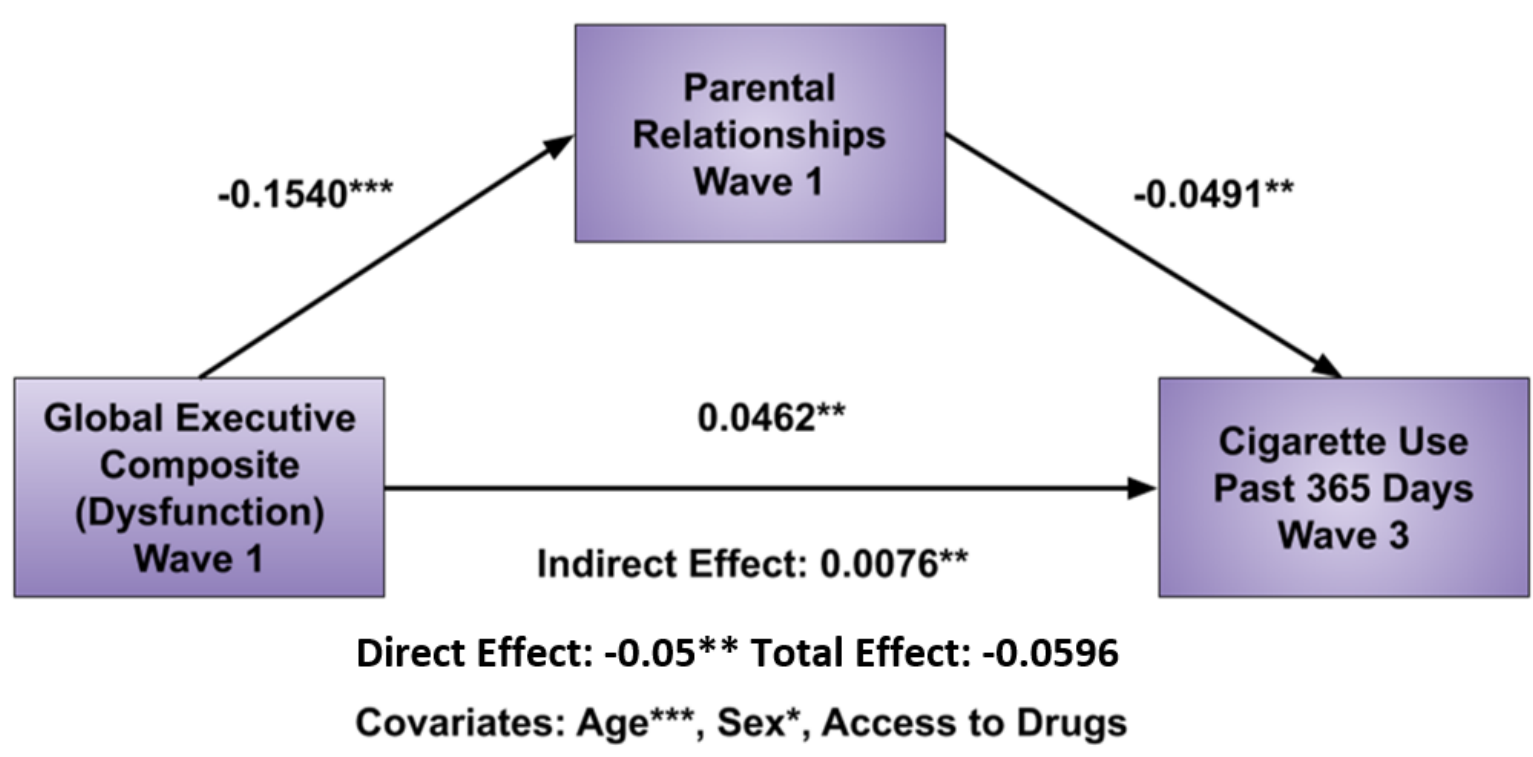

Figure 4: A multivariate longitudinal mediation model for the latent variable global executive composite (wave 1) from the BRIEF-2 GEC, predicting binary cigarette use (wave 3) from the CDDR, mediated by the latent variable parental relationships (wave 1) from the Parental Relationship Scale. All regression paths were found to be significant at the $p<0.01$ level of confidence. 


\section{Observed Differences in Executive Functions and Parental Relationships}

\section{Between Cigarette and Non-Cigarette Smokers}

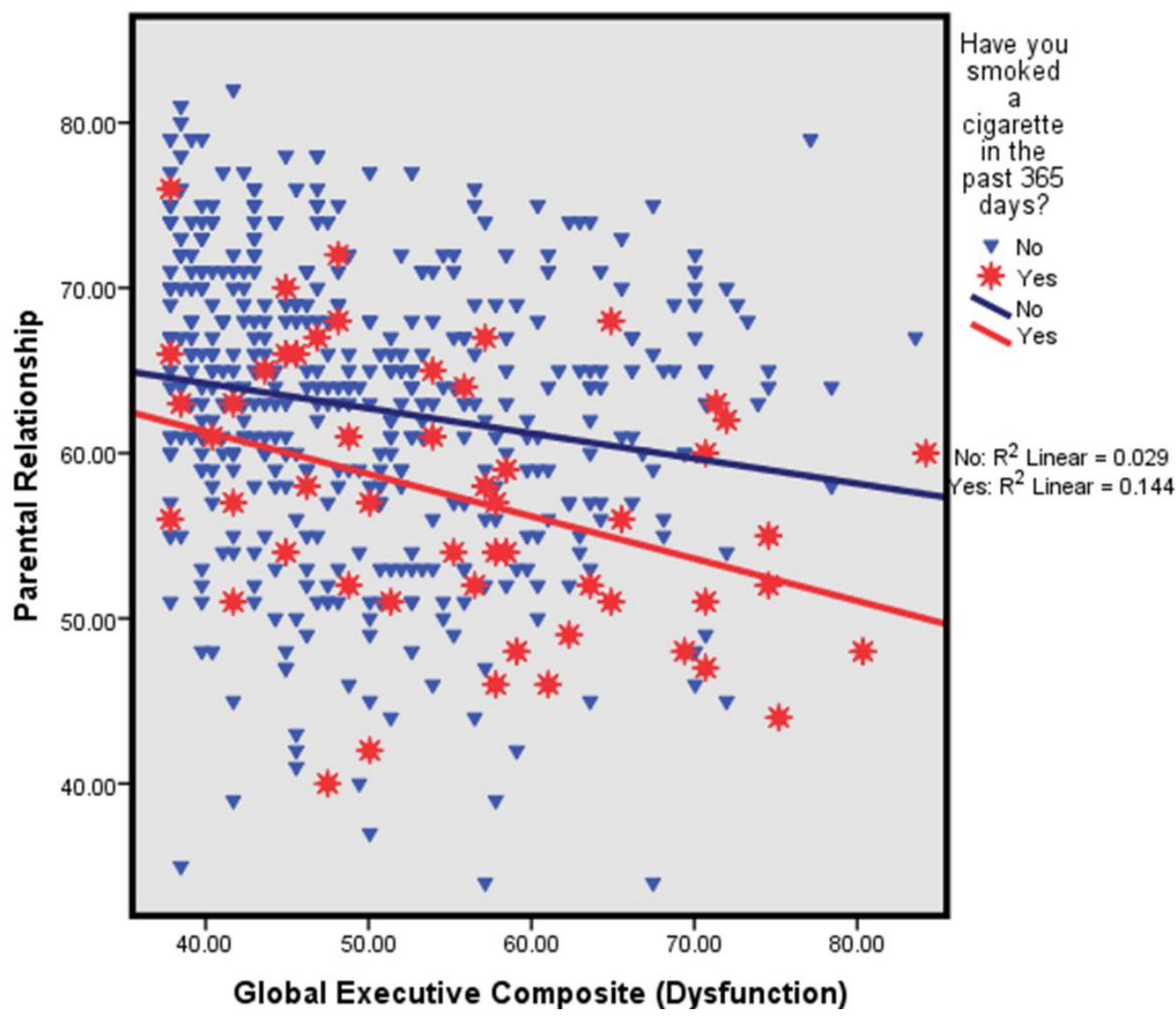

Figure 5: Higher BRIEF-2 GEC (associated with executive dysfunction) and a lower parental relationship score (associated with a distant parental relationship) was significantly associated with cigarette use. 
EXECUTIVE FUNCTIONS, RELATIONSHIPS, AND CIGARETTES

\section{Comparing Executive Functions Between Cigarette and Non-Cigarette Smokers}

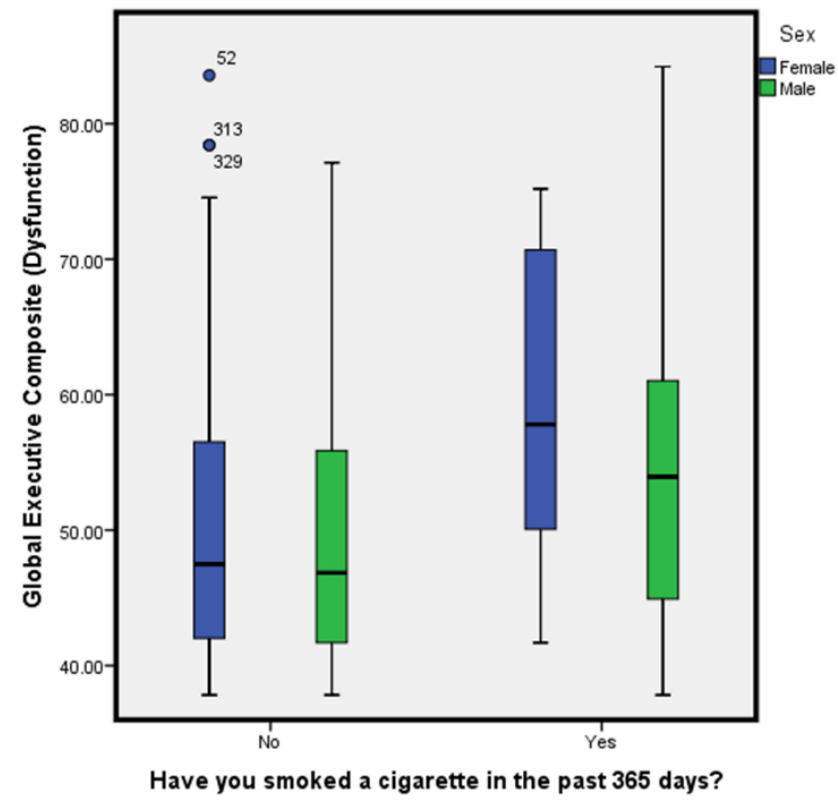

Figure 6: BRIEF-2 Global Executive Composite Scores did not significantly differ by gender (Global Executive Composite: Females: $(M=51.0, S D$ 10.5); Males: $(M=50.2, S D=10) ; t(501)=0.880, p=$ $0.379)$. 


\section{Comparing Parental Relationships Between Cigarette and Non-Cigarette Smokers}

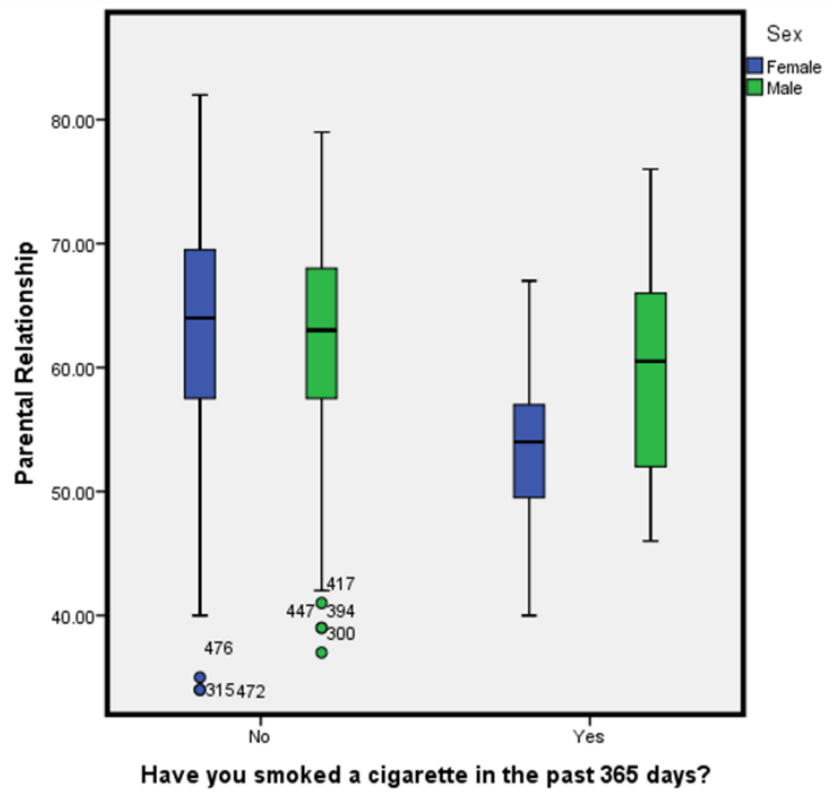

Figure 7: The parental relationship scores did not differ by gender (Parental Relationship Scale: Female:

$(M=62.2, S D=9.3) ;$ Male $(M=62.1, S D=8.4) ; t(498)=0.053, p=0.958)$ 
Observed Sex Differences in the Probability of Smoking Cigarettes for Youth Aged 12-18

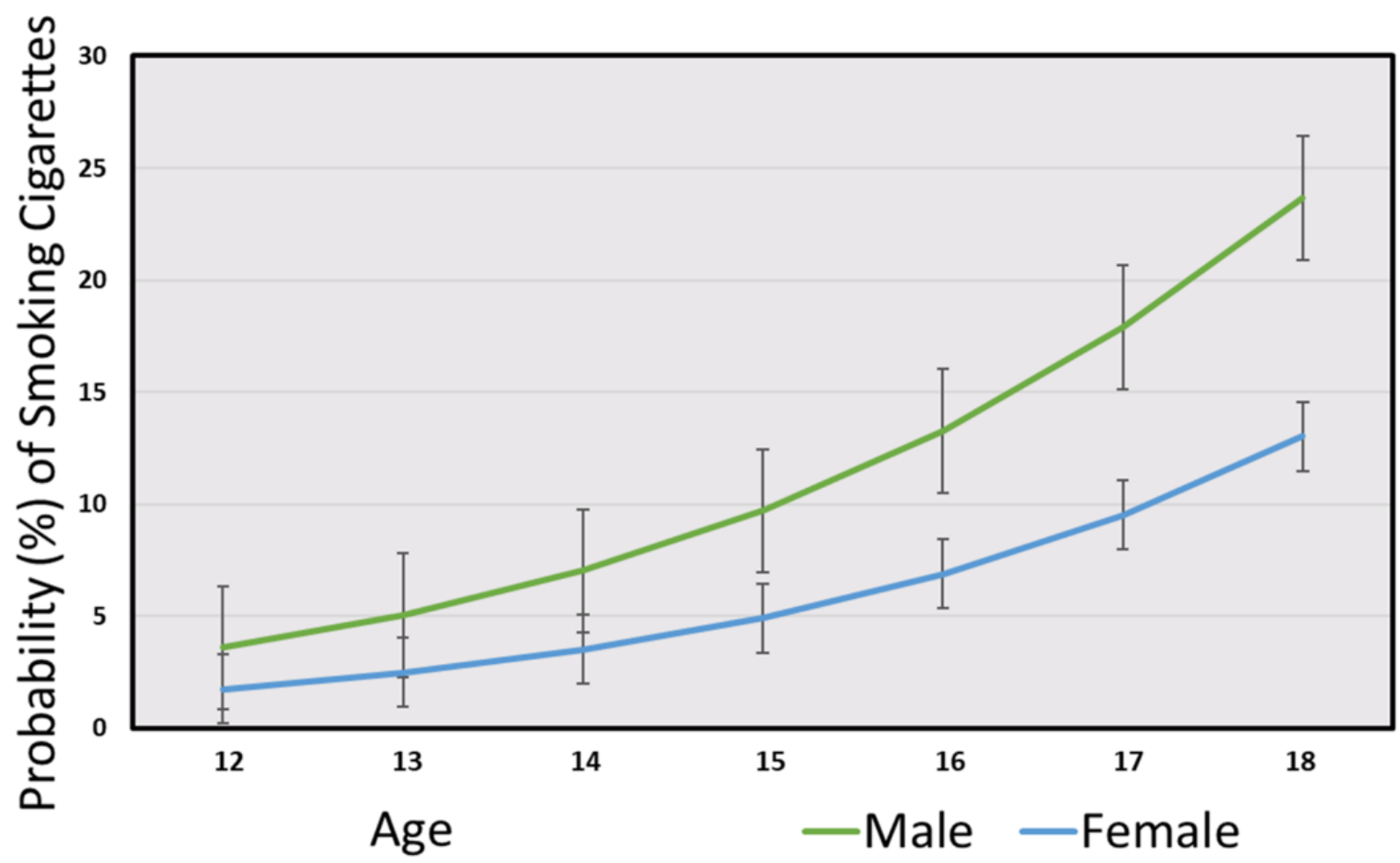

Figure 8: Coefficients obtained from model 1 were used to construct odds ratios for an average participant in the model. The odds ratios were then converted to probability and used to assess age differences across the sample population between males and females. 